\title{
Attention-deficit/hyperactivity disorder: the impact of methylphenidate on working memory, inhibition capacity and mental flexibility
}

\author{
Transtorno do déficit de atenção/hiperatividade (TDAH): o impacto do metilfenidato na \\ memória operacional, capacidade inibitória e flexibilidade mental
}

Cristiana Bolfer' ${ }^{1}$, Sandra Pasquali Pacheco², Miriam Harumi Tsunemi², Walter Souza Carreira ${ }^{4}$, Beatriz Borba Casella ${ }^{5}$ Erasmo Barbante Casella,

\begin{abstract}
Objective: To compare children with attention-deficit/hyperactivity disorder (ADHD), before and after the use of methylphenidate, and a control group, using tests of working memory, inhibition capacity and mental flexibility. Methods: Neuropsychological tests were administrated to 53 boys, 9-12 years old: the WISC-III digit span backward, and arithmetic; Stroop Color; and Trail Making Tests. The case group included 23 boys with ADHD, who were combined type, treatment-naive, and with normal intelligence without comorbidities. The control group $(n=30)$ were age and gender matched. After three months on methylphenidate, the ADHD children were retested. The control group was also retested after three months. Results: Before treatment, ADHD children had lower scores than the control group on the tests $(p \leq 0.001)$ and after methylphenidate had fewer test errors than before $(p \leq 0.001)$ Conclusion: Methylphenidate treatment improves the working memory, inhibitory control and mental flexibility of ADHD boys.
\end{abstract}

Keywords: attention deficit disorder with hyperactivity; working memory; methylphenidate.

\section{RESUMO}

Objetivo: Comparar crianças com transtorno de déficit de atenção/hiperatividade (TDAH) com controles, utilizando testes de memória de trabalho, capacidade inibitória e flexibilidade mental, em meninos de 9 a 12 anos. Métodos: Testes neuropsicológicos administrados: teste de ordem inversa dos dígitos, teste aritmético (WISC-III), Teste Stroop e Teste de Trilhas. Grupo experimental meninos ( $\mathrm{n}=23$ ), com TDAH combinado, virgens de tratamento, inteligência normal sem comorbidades. Grupo controle $(n=30)$ com as mesmas características do grupo experimental em termos de idade e sexo. Após três meses com metilfenidato, os grupos TDAH e controle foram novamente testadas. Resultados: Antes do tratamento, as crianças com TDAH apresentaram menor pontuação do que o grupo controle nos testes analisados $(p \leq 0.001$ ) e o grupo com TDAH apresentou menos erros nos testes após metilfenidato ( $p \leq 0.001$ ). Conclusão: 0 tratamento com metilfenidato melhora a memória de trabalho, controle inibitório e flexibilidade mental de meninos com TDAH.

Palavras-chave: transtorno de déficit de atenção com hiperatividade; memória de curto prazo; metilfenidato.

Attention-deficit/hyperactivity disorder (ADHD) is the most common behavioural disorder of childhood, adolescence and adulthood with an estimated prevalence in children from $3 \%$ to $6 \%$. The worldwide prevalence of $\mathrm{ADHD}$ is about $5.2 \%$, according to a systematic review and meta regression analysis ${ }^{1,2}$.

A diagnosis of ADHD is fundamentally clinical, based on clear and well-defined operational criteria, derived from classification systems such as the Diagnostic and Statistical Manual of Mental Health Disorders, 2013 (DSM-5) ${ }^{1}$.

Executive functions (EFs) represent major functions that allow anticipation and the establishment of objectives, as well as the monitoring of results, by comparing them to the initial objective and reaching a final result. These abilities enable a human being to perceive stimuli in their environment,

\footnotetext{
${ }^{1}$ Universidade de São Paulo, Faculdade de Medicina, Departamento de Neurologia, São Paulo SP, Brasil;

¿Universidade de São Paulo, Faculdade de Medicina, Departamento de Pediatria, São Paulo SP, Brasil;

${ }^{3}$ Universidade de São Paulo, Instituto de Matemática e Estatística, São Paulo SP, Brasil;

${ }^{4}$ Centro Universitário de Maringá, Maringá PR, Brasil;

${ }^{5}$ Universidade de São Paulo, Departamento de Pediatria, São Paulo SP, Brasil;

${ }^{6}$ Universidade de São Paulo, Faculdade de Medicina, Hospital das Clínicas, Instituto da Criança, Clínica de Deficiência de Aprendizagem, São Paulo SP, Brasil. Correspondence: Cristiana Bolfer; Avenida Rio Branco 917/Zona 05; 87015-380 Maringá PR, Brasil; E-mail: cristianaaprendizagem@gmail.com Conflict of interest: Erasmo Barbante Casella has worked as an advisor and speaker for Shire Pharmaceutical Company.

Received 15 August 2016; Received in final form 30 November 2016; Accepted 22 December 2016.
} 
respond dequately, change direction in a flexible ay, anticipate future objectives, consider the consequences and respond in an integrated way, using all these abilities to reach a final objective $e^{3,4,5,6,7}$.

Attention-deficit/hyperactivity disorder can be considered a neurobiological condition that presents with changes in some brain areas and their associated circuits, mainly the prefrontal and parietal cortex, cerebellum, and basal ganglia, which may imply problems in EF, such as working memory (WM), inhibition capacity (IC) and mental flexibility (MF) ${ }^{7.8}$.

Working memory is an EF that is characterized as a complex cognitive mechanism to maintain, control and manipulate relevant information. It is considered the "online memory" that allows a person to understand what is happening at the moment. It is retained just for a few seconds, to enable understanding of the rest of the story or context. Deficits related to WM affect the ability to maintain control, and manipulate goal-related information ${ }^{7,8}$.

Another important characteristic of ADHD from a neuropsychological point of view has been widely debated. Barkley's theory proposes a deficit specifically in behavior inhibition. This view considers inhibitory processes as a core deficit in ADHD that secondarily disrupts other $\mathrm{EF}$ processes ${ }^{6}$. Adaptive inhibition requires a multitude of interrelated processes, such as the monitoring of behavior, sustained attention, conflict detection and others, before the inhibition of theplanned course of action and the behavior can be adjusted according to the moment ${ }^{7,8,9,10,11}$.

A wide variety of neuropsychological tests indicate that ADHD children exhibit relatively weak, or sub-average, performances on various $\mathrm{EFs}^{5,6,7,7,9,10,11,1,12,13,14,15,16,17}$.

Stimulants are the most commonly-used medications in the treatment of $\mathrm{ADHD}$ and their clinical efficacy is well established ${ }^{14}$. However, research on the effect of methylphenidate on EF has produced uncertain results. Pietrzak et al. ${ }^{15}$ found that methylphenidate improved performance in MF and IC tasks in $71.4 \%$ and $69.7 \%$ of studies, respectively. However, improvement in WM tasks occurred in only $50 \%$ of the studies ${ }^{15}$.

The aim of the current study, therefore, was to assess the EFs (WM, IC and MF) of children with ADHD, and also to evaluate the evolution after three months of methylphenidate therapy.

\section{METHODS}

A group of 23 individuals was selected. Inclusion criteria were: treatment naïve with methylphenidate; male; ages 9-12 years $(\mathrm{m}=10.13, \mathrm{SD}=1.10)$; clinical diagnosis of $\mathrm{ADHD}$ combined type, based on criteria of the Diagnostic and Statistical Manual of Mental Disorders (4th ed.; DSM-IV ${ }^{17}$ ), $\mathrm{IQ} \geq 89(\mathrm{~m}=105.61, \mathrm{SD}=12.13)$; and no comorbidities. After the initial screening with SNAP-IV ${ }^{18}$ by a child neurologist, children were included or not, according the DSM-IV ${ }^{17}$.
The control group had 30 children, IQ $(\mathrm{m}=116.38$, $\mathrm{SD}=9.85)$. They were public school students, age $(\mathrm{m}=10.25$, $\mathrm{SD}=1.15)$ and gender-matched. The SNAP-IV ${ }^{18}$ questionnaire was applied to the control group. Teachers and parents reinforced that the children did not have symptoms suggested of hyperactivity, impulsiveness or inattention.

The exclusion criteria for both groups were: regular use of medication, visual, hearing, heart, rheumatic, orthopedic or neurological disabilities and severe behavioral disorders.

Treatment was with methylphenidate $0.3-0.5 \mathrm{mg} / \mathrm{kg}$ immediate release, twice a day. All participants were free from any other type of treatment with medication or interventions during the period of the study.

This study was approved by the Ethics Committee. All participating parents and teachers gave written consent and the children gave written assent.

\section{Tests}

All ADHD children were administered tests before, and three months after methylphenidate, which was given one hour before the sessions.

Neuropsychological tests were used to assess WM, IC and MF.

The neuropsychological tests were conducted by an experienced child neuropsychologist during single sessions. Both ADHD and control group children were re-evaluated after three months with the SNAP-IV questionnaire with the same tests. The ADHD children were tested over three days in a week. In the first and second session they completed the Wechsler Intelligence Scale for Children-3rd edition (WISC III) ${ }^{19}$. In the third session, they completed the Trail Making Test -Part B ${ }^{20}$ and Stroop Color Test - Word Interference Card ${ }^{21}$.

The WM was measured using two subtests from the WISC III: digit span backward and arithmetic. On the digit span backward, the child has to repeat a sequence of numbers read out by the examiner, in reverse order. The WM was measured using the total score for the backward version of the digit span subtest. In this study, the scores were standardized into each individual score. The arithmetic subtest comprised 20 elementary arithmetic problems. These problems were posed as oral questions to be solved without paper and pencil. The arithmetic test also measured systematic problem-solving abilities ${ }^{19}$.

The neuropsychological test used to assess MF was the Trail Making Test - Part B. The test requires the child to draw pencil lines alternating between consecutive numbers and letters in ascending order (e.g., 1-A-2-B-3-C). During the test, the child could not lift the pencil off the paper ${ }^{20}$.

The IC was measured using the Stroop Color Test (Victoria Version) - Word Interference Card. The children were instructed to name the color of the ink and not what was written (e.g., the word BLUE in red ink). Score errors were calculated by extracting only the uncorrected errors, and not self-corrected errors. In this study, we analysed only the commission errors ${ }^{21}$. 


\section{Statistical analyses}

The $t$-Student, was used to compare the performance of the ADHD group and their individually matched controls on measures of WM, IC and MF. Statistical significance was set at the $\mathrm{p}<0.05$ level. Receiver-operating characteristic curves were conducted to compare diagnostic tests. Statistical significance was set when the area exceeded $80 \%$. Effect size classification, according to Cohen ${ }^{22,23}$, is given as $\mathrm{d}=0.02$ to 0.15 corresponding to a small effect, $\mathrm{d}=.015$ to 0.35 corresponding to a medium effect, and $d>0.35$ representing a large effect $^{23}$.

\section{RESULTS}

The results for all task evaluations showed that before methylphenidate, scores were significantly lower in the ADHD children than in the control group.

Table 1 shows the performance on measures of WM, IC and MF in the ADHD group $(\mathrm{n}=23)$ and the matched control group $(\mathrm{n}=30)$ in the first evaluation.

Table 2 shows the results of the control group in the first evaluation and after three months, and the results of the ADHD group before and after three months of treatment. The ADHD group had the best results after three months of methylphenidate, a change that was not seen in the control group.

Table 3 shows the receiver-operating characteristic curves and the effect on the ADHD group before and after three months of treatment. The ADHD group had high results on their WM, IC and MF after three months of methylphenidate.

Table 4 shows the results of inattention and hyperactivity for the control group and $\mathrm{ADHD}$ children at the beginning of the study; the ADHD group before and after three months of treatment; and the control group before and after three months.

\section{DISCUSSION}

The aim of this study was to compare the performances of ADHD in children (9-12-year-old boys) before and after treatment with methylphenidate with a control group, using tests of WM, IC and MF. The medication effect results showed a significant alteration in WM, IC and MF as well as an EF effect.

Although $\mathrm{ADHD}$ and $\mathrm{EF}$ disturbances are frequently related, the executive disorder is neither pathognomonic, nor necessary, for the $\mathrm{ADHD}$ diagnosis. Children without $\mathrm{ADHD}$ may also present with some executive disorder and many individuals with $\mathrm{ADHD}$ do not show significant impairment in tests that analyze $\mathrm{EF}^{3,24}$. Brown ${ }^{24}$ highlights the importance of changes in the EFs in the daily activities of people with ADHD.

As the EFs are a group of cognitive functions that include inhibition, response selection and alteration, behavioural monitoring and WM, it is considered that children with $\mathrm{ADHD}$ exhibit a range of difficulties, which results in a worse performance compared to individuals without $\mathrm{ADHD}^{6,7,10,25,26,27,28,29,30}$.

Our results are consistent with many studies on neuropsychological evaluation and ADHD, showing an improvement in WM, IC, and MF, as well as a relevant medication effect on EF performance at various levels ${ }^{11,13,15,27,28}$.

Other studies that also analyzed attention and EF, and the effects of methylphenidate treatment in children with ADHD, did not find similar results to ours, but most of them

Table 1. Performance on measures of working memory, inhibitory control and mental flexibility, in ADHD ( $\mathrm{n}=23$ ) and matched Control Group ( $n=30)$ in the first assessment.

\begin{tabular}{|c|c|c|c|}
\hline Measure & ADHD M (SD) & Control Group M (SD) & $\mathrm{p}$ \\
\hline Digit span backward & $3.4(1.1)$ & $4.6(0.8)$ & $<0.001$ \\
\hline Arithmetic & $10.6(2.8)$ & $12.4(2.2)$ & 0.011 \\
\hline Trail making test part B (time) & $4.6(4.7)$ & $2.2(2.2)$ & 0.017 \\
\hline Stroop color test - Word interference card (errors) & $72.0(31.6)$ & $55.4(26.5)$ & 0.033 \\
\hline
\end{tabular}

ADHD: attention-deficit/hyperactivity disorder; M: mean; SD: standard deviation; $\mathrm{p}$ : t-student probability statistical significance was set at the p 0.05 level.

Table 2. Performance on measures of working memory, inhibitory control and mental flexibility in both groups in the first, and second time of evaluation.

\begin{tabular}{|c|c|c|c|c|c|c|}
\hline \multirow{3}{*}{ Measure } & \multicolumn{3}{|c|}{ Control group } & \multicolumn{3}{|c|}{ ADHD } \\
\hline & Before & After three months & & Before & After three months & \\
\hline & $M(S D)$ & $M(S D)$ & $p$ & $M(S D)$ & $M(S D)$ & $p$ \\
\hline Digit span backward & $4.6(0.8)$ & $4.8(0.8)$ & 0.094 & $3.4(1.1)$ & $4.9(1.2)$ & $<0.001$ \\
\hline Arithmetic & $12.4(2.2)$ & $12.5(2.1)$ & 0.502 & $10.6(2.8)$ & $13.1(2.9)$ & $<0.001$ \\
\hline Trail making test part B (time) & $55.4(26.5)$ & $53.5(28.0)$ & 0.188 & $4.6(4.7)$ & $0.7(0.8)$ & $<0.001$ \\
\hline Stroop color test - Word interference card (errors) & $2.2(2.2)$ & $1.9(2.1)$ & 0.125 & $72.0(31.6)$ & $47.8(15.1)$ & $<0.001$ \\
\hline
\end{tabular}

ADHD: attention-deficit/hyperactivity disorder; M: mean; SD: standard deviation; $\mathrm{p}$ : $\mathrm{t}$-student probability statistical significance was set at the $\mathrm{p}<0.05$ level. 
Table 3. Performance on measures of working memory, inhibitory control and mental flexibility in ADHD group, before and after treatment.

\begin{tabular}{lcc}
\hline \multirow{2}{*}{ Measure } & \multicolumn{2}{c}{ ADHD Before / After MPH } \\
\cline { 2 - 3 } & ROC & Cohen's d \\
\hline Digit span backward & 0.870 & 1.455 \\
Arithmetic & 0.899 & 1.285 \\
Trail making test part B (time) & 0.882 & 0.832 \\
$\begin{array}{l}\text { Stroop color test - Word } \\
\text { interference card (errors) }\end{array}$ & 0.843 & 0.960 \\
\hline
\end{tabular}

ADHD: attention-deficit/hyperactivity disorder; MPH: methylphenidate; ROC: Receiver-operating characteristic, statistical significance was set at the area $>80 \%$; Cohen's d: effect size by $d=0.02$ to 0.15 small effect, $d=0.15$ to 0.35 medium effect, and $d>0.35$ large effect.

did not have the same degree of selection of individuals, without comorbidities, same sex and narrow age range as specified in our study ${ }^{27,28,31}$. We believe that the different results found in these studies may be associated with the absence of the specifications and other factors that could be related.

In our study, the ADHD children showed changes in the EF than that observed in other studies with adults, which may be related to the fact that in children, the brain maturation is still developing and the differences in control is greater at this time. These impairments may interfere with academic progress and disrupt activities of daily living at home and in social settings $\mathrm{s}^{25}$.

Normative data on typical children have shown adequate developmental progression, highlighting the differences between the first assessment and after methylphenidate in the children with ADHD. These results suggest that these measures provide an important tool to assess children at risk for $\mathrm{ADHD}$ showing deficits in attention areas and $\mathrm{EF}^{11,13,15,27,28,31}$.

We used the WISC III digit span backward and arithmetic tests to evaluate WM abilities ${ }^{19}$. It is important to emphasize that these tasks also assess selective attention (the ability to focus the cognitive resources on information relevant to our goals), which is important to processes the different stages of WM. Our data indicated that ADHD treatment demonstrated a significant increase in WM and we believe that it was through an increase of selective attention ${ }^{27}$.

In the current literature, IC by commission errors can also be evaluated with the Stroop Color Test - Word Interference Card. The test is used as a measure of the inhibition capacity function. Indeed, it is often referred to as a measure of the specific inhibition's controlling behavior (e.g., prepotent response). The Stroop Color Test - Word Interference Card creates a conflict between the stimuli of color naming and color reading. Errors made during the performance on the Word Interference Card most likely represent a result of inhibiting the prepotent impulse ${ }^{14}$.

Although the Stroop Test commission errors were used for analysis of inhibition function (e.g., impulsivity), it is important to note that the test interferes with selective and sustained attention, WM and self-control ${ }^{7,14}$. The current study showed that errors in the Stroop interference effect could be
Table 4. Results concerning the subscales (inattention; hyperactivity) of the SNAP-IV for the control group and ADHD (attention-deficit/hyperactivity disorder) children.

\begin{tabular}{lccccc}
\hline \multirow{2}{*}{ First time } & \multicolumn{2}{c}{ Teacher } & & \multicolumn{2}{c}{ Parents } \\
\cline { 2 - 3 } Control group & I & H & & I & $H$ \\
\hline M & 0.303 & 0.5 & & 0.5 & 0.6 \\
SD & 0.299 & 0.5 & & 0.5 & 0.5 \\
ADHD & & & & \\
M & 2.161 & 1.7 & & 2.3 & 2.2 \\
SD & 0.853 & 1.0 & & 0.6 & 0.7 \\
P & $<0.001$ & $<0.001$ & $<0.001$ & $<0.001$ \\
ADHD & & & &
\end{tabular}

Before MPH

\begin{tabular}{|ccccc}
\hline M & 2.161 & 1.7 & 2.3 & 2.2 \\
\hline SD & 0.853 & 1.0 & 0.6 & 0.7 \\
\hline After MPH & & & & \\
\hline M & 1.263 & 0.9 & 1.3 & 1.3 \\
\hline SD & 0.495 & 0.7 & 0.5 & 0.7 \\
\hline P & $<0.001$ & $<0.001$ & $<0.001$ & $<0.001$ \\
\hline Control group & & & & \\
Before three months & & & & \\
M & 0.304 & 0.546 & 0.477 & 0.646 \\
\hline SD & 0.309 & 0.5 & 0.5 & 0.5 \\
\hline After three months & & & & \\
\hline M & 0.346 & 0.546 & 0.477 & 0.646 \\
\hline SD & 0.283 & 0.5 & 0.5 & 0.5 \\
\hline P & 0.002 & - & - & - \\
\hline
\end{tabular}

ADHD: attention-deficit/hyperactivity disorder.; M: mean; SD: standard deviation; $p$ : t-student probability statistical significance was set at the $p<$ 0.05 level; MPH: methylphenidate; I: inattention; $\mathrm{H}$ : hyperactivity.

explained mainly by impulsivity and that it represents a good marker for response to treatment

In this way, the improvement in IC in the ADHD group with methylphenidate can be correlated with the assessment of SNAP-IV, and this is consistent with the arguments that ADHD children have difficulty in inhibiting impulses.

On the point of MF, our findings appear consistent with the study by Hale et al. ${ }^{26}$, which found differences in the Trail Making Test - Part B errors, between ADHD children and a control group, corroborating that, generally, ADHD children needed more time to complete the test than the control group. This is an indication of slower set-shifting, which suggests that children with ADHD are less capable of divided attention ${ }^{26,32}$.

Our results showed noticable deficits in WM, IC and MF in children with ADHD. These deficits may be associated with poor attention or hyperactivity and also with poor levels of EF. We emphasize that after methylphenidate treatment, ADHD children showed a great improvement in the EFs analyzed, achieving results similar to those of the control group

As limitations of our study, we considered the small number of children included in the current trial and the fact that we did not investigate ADHD subtypes.

In conclusion, EF deficits are important components in the neuropsychology of ADHD, and the neuropsychological 
assessments showed a high index of changes in EF in boys with ADHD. Moreover, there is a strong correlation between the outcome of methylphenidate treatment and clinical improvement.
An improvement of working memory, inhibition capacity and flexibility deficits in boys, 9-12 years of age, with ADHD combined type, was noted in all these domains after the administration of methylphenidate.

\section{References}

1. American Psychiatric Association. Diagnostic and statistical manual of mental disorders. 5th ed. Arlington: American Psychiatric Publishing; 2013.

2. Polanczyk G, Lima MS, Horta BL, Biederman J, Rohde LA. The worldwide prevalence of ADHD: a systematic review and metaregression analysis. Am J Psychiatry. 2007;164(6):942-8. https://doi.org/10.1176/ajp.2007.164.6.942

3. Mesulam M. Principles of behavioral neurology. Philadelphia: F.A. Davis; 1985.

4. Skogan AH, Zeiner P, Egeland J, Urnes AG, Reichborn-Kjennerud T, Aase $\mathrm{H}$. Parent ratings of executive function in young preschool children with symptoms of attention-deficit/-hyperactivity disorder. Behav Brain Funct. 2015;11(1):16-28. https://doi.org/10.1186/s12993-015-0060-1

5. Dovis S, Van der Oord S, Wiers RW, Prins PJ. What part of working memory is not working in ADHD? Short-term memory, the central executive and effects of reinforcement. J Abnorm Child Psychol. 2013;41(6):901-17. https://doi.org/10.1007/s10802-013-9729-9

6. Barkley RA. Behavioral inhibition, sustained attention, and executive functions: constructing a unifying of ADHD. Psychol Bull. 1997;121(1):65-94. https://doi.org/10.1037/0033-2909.121.1.65

7. Diamond A. Executive functions. Annu Rev Psychol. 2013;64(1):135-68. https://doi.org/10.1146/annurev-psych-113011-143750

8. Rhodes SM, Booth JN, Palmer LE, Blythe RA, Delibegovic M, Wheate NJ. Executive functions predict conceptual learning of science. Br J Dev Psychol. 2016;34(2):261-75. https://doi.org/10.1111/bjdp.12129

9. Bari A, Robbins TW. Inhibition and impulsivity: behavioral and neural basis of response control. Prog Neurobiol. 2013;108:44-79. https://doi.org/10.1016/j.pneurobio.2013.06.005

10. Davidson MC, Amso D, Anderson LC, Diamond A. Development of cognitive control and executive functions from 4 to 13 years: evidence from manipulations of memory, inhibition, and task switching. Neuropsychologia. 2006;44(11):2037-78. https://doi.org/10.1016/j.neuropsychologia.2006.02.006

11. Tucha O, Prell S, Mecklinger L, Bormann-Kischkel C, Kübber S, Linder M et al. Effects of methylphenidate on multiple components of attention in children with attention deficit hyperactivity disorder. Psychopharmacology. 2006;185(3):315-26. https://doi.org/10.1007/s00213-006-0318-2

12. Fan LY, Gau SF, Chou TL. Neural correlates of inhibitory control and visual processing in youths with attention deficit hyperactivity disorder: a counting Stroop functional MRI study. Psychol Med. 2014;44:2661-71.

13. Yang L, Cao Q, Shuai L, Li H, Chan RC, Wang Y. Comparative study of OROS-MPH and atomoxetine on executive function improvement in ADHD: a randomized controlled trial. Int J Neuropsychopharmacol. 2012;15(1):15-26. https://doi.org/10.1017/\$1461145711001490

14. Sørensen L, Plessen KJ, Adolfsdottir S, Lundervold AJ. The specificity of the Stroop interference score of errors to ADHD in boys. Child Neuropsychol. 2014;20(6):677-91. https://doi.org/10.1080/09297049.2013.855716

15. Pietrzak RH, Mollica CM, Maruff P, Snyder PJ. Cognitive effects of immediate-release methylphenidate in children with attention-deficit/hyperactivity disorder. Neurosci Biobehav Rev. 2006;30(8):1225-45. https://doi.org/10.1016/j.neubiorev.2006.10.002
16. Coghill DR, Rhodes SM, Matthews K. The neuropsychological effects of chronic methylphenidate on drug-naive boys with attention-deficit/hyperactivity disorder. Biol Psychiatry. 2007;62(9):954-62. https://doi.org/10.1016/j.biopsych.2006.12.030

17. American Psychiatric Association. Diagnostic and statistical manual of mental disorders. 4th ed. Washington, DC: American Psychiatric Association; 1994

18. Mattos P, Serra-Pinheiro MA, Rohde LA, Pinto D Apresentação de uma versão em português para uso no Brasil do instrumento MTA-SNAP-IV de avaliação de sintomas de transtorno do déficit de atenção/hiperatividade e sintomas de transtorno desafiador e de oposição Rev Psiquiatr Rio Gd Sul. 2006;28(3):1-19. https://doi.org/10.1590/S0101-81082006000300008

19. Wechsler D.WISC III: escala de inteligência Wechsler para crianças: manual/David Wechsler 3a ed: adaptação e padronização de uma amostra Brasileira. São Paulo: Casa do Psicólogo; 2002.

20. Reitan RM. Trail making test manual for administration and scoring. Arizona: Reitan Neuropsychology Laboratory; 1992.

21. Duncan MT. Obtenção de dados normativos para desempenho no teste de Stroop num grupo de estudantes do ensino fundamental em Niterói. São Paulo: Hospital das Clínicas da Faculdade de Medicina da Universidade de São Paulo; 2003

22. Pagano M, Gauvreau K. Princípios de bioestatística. São Paulo: Pioneira Thompson Learning; 2004.

23. Lindenau JD, Guimarães LSP. Calculating the effect size in SPSS. Rev HCPA. 2012;32(3):363-81. Portuguese.

24. Brown TE. Executive functions and attention deficit hyperactivity disorder: implications of two conflicting views. Int J Disabil Dev Educ. 2006;53(1):35-46. https://doi.org/10.1080/1034912050051002

25. Shaw P, Eckstrand K, Sharp W, Blumenthal J, Lerch JP, Greenstein D et al. Attention-deficit/hyperactivity disorder is characterized by a delay in cortical maturation. Proc Natl Acad Sci USA. 2007;104(49):19649-54. https://doi.org/10.1073/pnas.0707741104

26. Hale JB, Reddy LA, Decker SL, Thompson R, Henzel J, Teodori A et al. Development and validation of an attention-deficit/hyperactivity disorder (ADHD) executive function and behavior rating screening battery. J Clin Exp Neuropsychol. 2009;31(8):897-912. https://doi.org/10.1080/13803390802687423

27. Dopheide JA. The role of pharmacotherapy and managed care pharmacy interventions in the treatment of ADHD. Am J Manag Care. 2009;15(Suppl 5):S141-50.

28. Coghill D. Use of stimulants for attention deficit hyperactivity disorder:FOR. BMJ. 2004;329(7471):907-8. https://doi.org/10.1136/bmj.329.7471.907

29. Gazzaley A, Nobre AC. Top-down modulation: bridging selective attention and working memory. Trends Cogn Sci. 2012;16(2):129-35. https://doi.org/10.1016/j.tics.2011.11.014

30. Bolfer C, Casella EB, Baldo MV, Mota AM, Tsunemi MH, Pacheco SP. Reaction time assessment in children with ADHD. Arq Neuropsiquiatr. 2010;(2):282-6. https://doi.org/10.1590/S0004-282X2010000200025

31. Cao AH, Yu L, Wang YW, Wang JM, Yang LJ, Lei GF. Effects of methylphenidate on attentional set-shifting in a genetic model of attention-deficit/hyperactivity disorder. Behavioral and Brain Functions. 2012;8(1):10-21. https://doi.org/10.1186/1744-9081-8-10

32. Moriguchi Y, Hiraki K. Prefrontal cortex and executive function in young children: a review of NIRS studies. Front Hum Neurosci. 2013;7:867-76. https://doi.org/10.3389/fnhum.2013.00867 